\title{
Evolution from Stroke Risk Factors to Brain Health Determinants
}

11 th Johann Jacob Wepfer Lecture, European Stroke Conference, Vienna, Austria 2015

Ralph L. Sacco

Olemberg Family Chair in Neurological Disorders, Miller Professor of Neurology, Public Health Sciences, Human Genetics, and Neurosurgery, Executive Director, Evelyn McKnight Brain Institute, Miller School of Medicine, University of Miami, Chief of Service, Jackson Memorial Hospital, Miami, Fla., USA

\section{THE JOHANN JACOB WEPFER AWARD}
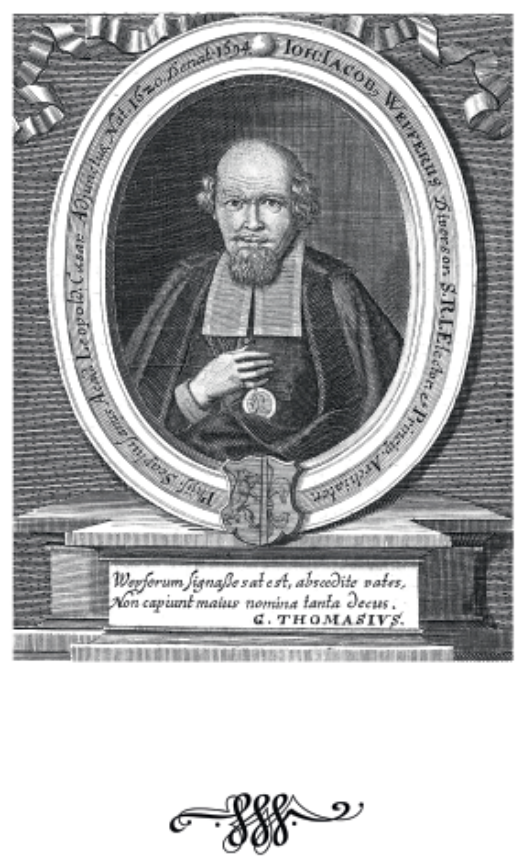

THE JOHANN JACOB WEPFER AWARD OF THE

EUROPEAN STROKE CONFERENCE 2015

AND THE

EUROPEAN STROKE RESEARCH FOUNDATION

IS DEDICATED TO

PROF. RALPH L. SACCO, MD MIAMI, FLORIDA (USA)

FOR OUTSTANDING CLINICAL AND RESEARCH WORK IN THE FIELDS OF STROKE MANAGEMENT AND STROKE PREVENTION WITH PARTICULAR VIEW TO ASSOCIATED COMORBIDITIES VIENNA, MAY $15^{\text {TH }}, 2015$

M. G. HENNERICI PRESIDENT OF DENT OF THE ESRF 
I wish to sincerely thank the organizing committee for inviting me over to this conference. I am incredibly humbled to be here to present the 11th Wepfer lecture. Several years ago, I sat at this same European Stroke Conference and listened to the many distinguished Wepfer lecturers, some of whom are in this audience today; so it is really a tremendous honor and privilege to be here to deliver this lecture.

I would not be here today if not for the outstanding mentorship that I have been fortunate to have over the years. It is critical for all of us to reflect on the importance of the mentor-mentee relationship. Mentorship has meant so much to me in my career and I am sure it is the same for many of your own careers. Dr. Phil Wolf, a principal investigator from the Framingham Study, was my first mentor in medical school. I started working with him as a second year medical student and spent a summer in the basement of the Framingham Study offices sorting computer cards. He introduced me to neurology and epidemiology and mentored me through my first publication on the outcomes of stroke and supported me as a first author [1]. After graduating from medical school, I moved to New York City for neurology residency at the Neurological Institute at Columbia Presbyterian. There I met Dr. J.P. Mohr, who supported my career development early on as a resident, stroke fellow, assistant professor and up the ladder. I am incredibly grateful for all his support and for always encouraging me to ask important questions and challenge widely accepted concepts. I was also fortunate to be mentored by Dr. Allan Hauser who helped me with epidemiology even though his field was epidemiology of epilepsy. I am also indebted to my first chairman, Dr. Bud Rolland, who convinced me to stay in academics and Dr. Tim Pedley who encouraged me to get further formal training with a Master's of Science in Epidemiology at the Mailman School of Public Health at Columbia. Without mentorship many of us would not be here today. I hope all of you leave this conference and continue to mentor other young students, fellows and faculty to pursue careers in stroke research.

I am also grateful to my collaborating team of investigators. I may be the one up here giving this lecture, but I share this award with all of the colleagues with whom I have had the pleasure of working. Not all of them are on this slide, but many of them are shown including Mitch Elkind, Professor of Neurology at Columbia and the coprincipal investigator for the Northern Manhattan Study (NOMAS); Tatjana Rundek, who made the trek with me to the University of Miami as my Vice Chairman for Clinical Translational Research; Clinton Wright, Scientific

Evolution from Stroke Risk Factors to Brain Health Determinants
Director of our McKnight Brain Institute who is really the mover behind some of the work that I am going to present today on brain health; and Marco Di Tullio, Professor of Medicine at Columbia and a cardiologist who has been a long-term collaborator. There are many other students, residents, fellows, faculty, and colleagues with whom I have had the privilege of working, including other European colleagues who aren't on this slide. I thank them for their support and helpful contributions along the way. Collaborations and teamwork are really the key ingredients to the success we have had in our programs.

The title of my lecture is 'Evolution from Stroke Risk Factors to Brain Health Determinants' (for summary points panel, see end of this article). Although this is the 24th European Stroke Conference, in the future this may evolve into the European Brain Health Conference. Some of the main concepts that I will amplify here are (1) traditional vascular risk factors are determinants of stroke, but brain health is also a determinant of stroke, and this will be an important concept to define more clearly as we think about the future; (2) factor combinations, as opposed to individual risk factors, are also incredibly important as we identify individuals who are at risk; (3) risk is usually continuous and cumulative and there are important precursor behavioral conditions that precede the actual risk factor; (4) sub-clinical vascular and brain measures are also determinants of brain health, and will enhance opportunities for us to detect and initiate treatment and prevention before one has a stroke or before one has a decrement in brain health; and (5) novel factors such as infectious burden and inflammatory markers are determinants of not only stroke, but also brain health.

In the welcome address to ESC 2015, we heard from Dr. Michael Hennerici about the continued importance of stroke worldwide. Every country is affected by the increasing public health burden due to stroke. In 2010, 16.8 million new strokes occurred - 68\% greater than in 1990 with greater incidence rates in low- to middle-income countries [2]. Moreover, 33 million people were living with stroke; more than double than what existed in 1990. Although incidence rates are lower in high-income countries, stroke prevalence is greater in high income than in low- to middle-income countries. Countries where people have a longer life span have a much higher prevalence of stroke; however, life expectancy is also increasing in low- to middle-income countries and consequently results in an increase in the number of stroke cases. Stroke, however, is probably only the tip of the iceberg.

Globally, we are seeing the aging patterns of our population. The number of people aged over 65 will rise from 
Table 1. Conditions that can be considered components of the brain health spectrum

\section{Stroke}

Dementia

Vascular cognitive impairment

Cognitive aging

Age-related memory loss

Vascular functional impairment

Subclinical brain and vascular disease

390 to 800 million by 2025 constituting nearly $10 \%$ of the population. The average life expectancy in 1995 was only 65 years but by 2025 it is expected to reach 73 years. By the year 2025, no country on the planet will have a life expectancy of $<50$. As we consider these demographic predictions, we need to consider the impact of stroke and brain health in humans.

The aging patterns of our populations will require us to evolve from control of stroke risk factors to consideration of the determinants of a broader concept of brain health. Although many of us are neurologists, or even more specialized as vascular neurologists, perhaps in the future we will be considered by the public more as brain healthcare providers. The broader spectrum of brain health encompasses stroke, dementia, vascular cognitive impairment, cognitive aging, age-related memory loss, vascular functional impairment, and subclinical vascular diseasesincluding white matterhyperintensities(WMHI), brain atrophy, silent brain infarctions, and cerebral microbleeds (table 1). The importance of cognitive aging was just addressed in an Institute of Medicine Report Entitled Cognitive Aging: Progress in Understanding and Opportunities for Action [3]. The broader definition of brain health allows us to consider how vascular risk factors have evolved to brain health determinants.

The term 'risk factor' was originally defined in 1961 by Dr. Bill Kannel, one of the leaders of the Framingham Heart Study, who I had the pleasure of knowing when I was a medical student [4]. In his prescient article, he wrote: 'since it has been established that coronary atherosclerosis is present for many years prior to the development of symptomatic coronary heart disease, it seems evident that efforts at prevention must begin many years before the appearance of clinical CHD'. That was in 1961 where he coined the term 'factors of risk'. We all now appreciate that these factors of risk or risk factors take years to develop. They do not happen overnight. In fact, Phil Wolf has stated: 'there was nothing accidental about stroke'. The term 'cerebrovascularaccident' is a misnomer, since there is nothing accidental about its occurrence; rather it takes many years of risk to eventually develop into a stroke.

Individuals advance over time from disease-free to the occurrence of sub-clinical disease to crossing that clinical threshold of developing symptoms. All too often, it is during that symptomatic stage that we get involved as physicians, sometimes too late to effectively prevent the occurrence of disease. Most individuals are born healthy, with or without a genetic predisposition for vascular disease, and subsequently develop induction behaviors that interact with sociocultural factors and lead to the development of risk factors. In the primordial development of risk factors, the individual is still in the disease-free stage. Sub-clinical disease begins to develop when risk factors are inadequately controlled, whether it is small amounts of plaque in the carotid or other arterial vessels, subclinical changes in myocardial function, or early changes in brain structure. The progression of subclinical disease can lead to an individual eventually crossing that clinical threshold. Therefore, most physicians, clinicians and healthcare providers are getting involved too late in the process. A patient may have already had a stroke, a TIA, or an MI, but then we are working at the end of the curve to reverse or alter progression of symptomatic disease. We should be thinking more broadly about focusing on the earlier stages of risk for stroke and brain health decline. We have made amazing strides in treating and preventing stroke and need to do the same for preventing other vascular morbidities including improving brain health.

As J.P. Mohr mentioned in his introduction, we started the NOMAS about 23 years ago. Many students, residents, fellows, faculty and colleagues have worked on this study that continues even today. Originally we sought to define the incidence of stroke across various ethnic groups in the race and ethnically diverse population of Northern Manhattan [5]. The study originated when I was at the Columbia University with NINDS grant support. When I packed my bags to move further south to warmer weather as the Chairman of Neurology at the University of Miami in 2007, the study was competitively renewed and continued. This success has been based on maintaining great teams in place across 2 universities and continuing to collaboratively work together as colleagues. NOMAS was originally designed as a stroke incidence study and population-based case-control study. After the first 5 -year grant cycle, the study was expanded and it evolved into a Framingham-like study design by enrolling a co- 
Fig. 1. Conceptual framework for the Northern Manhattan Study.

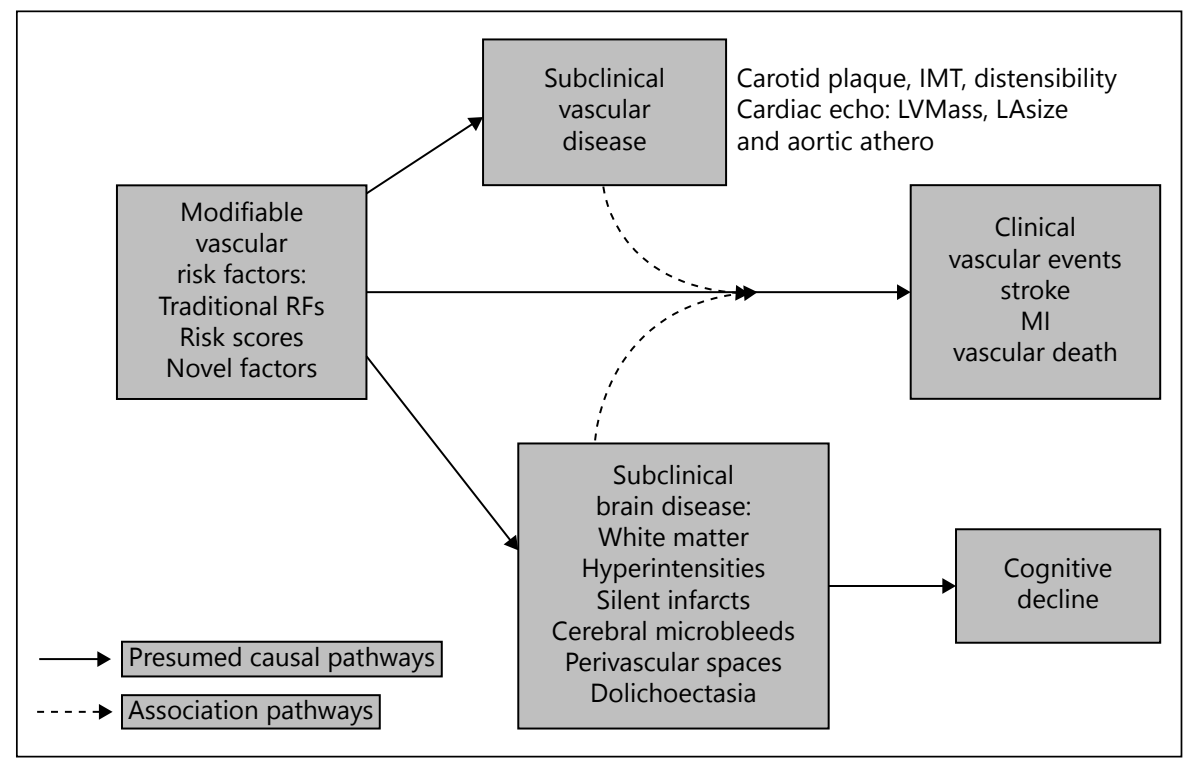

hort of 3,298 people who were prospectively followed annually originally for stroke, MI and vascular death. With each 5-year NINDS renewal, NOMAS evolved with new aims addressing traditional and novel vascular risk factors and measuring subclinical disease of the heart, carotids, and brain. Magnetic resonance imaging (MRI) of the brain and neuropsychological testing was completed on nearly 1,300 members of the cohort. Consequently, as the cohort aged, the primary focus has shifted from stroke to cognition, cognitive decline, and dementia. Therefore, NOMAS has evolved from a stroke risk factor study to a brain health study.

The conceptual framework of the study was to detect individual risk factors as it relates to clinical vascular events including stroke, MI and vascular deaths (fig. 1). Our earlier investigations were heavily focused on subclinical vascular measurements of the carotid. Dr. Tatijana Rundek has worked on quantitating the effects of carotid plaque and IMT and other measures on a variety of outcomes [6-10]. Working with cardiology colleagues, we evaluated many cardiac echo determinants of stroke including left ventricular mass, left atrial size, and patent foramen ovale [11-16]. More recently, we have been evaluating the brain MRIs and cognition and cognitive decline. Some of these associations have direct relationships with brain health, and some of them may have indirect relationships operating as intervening variables with traditional vascular risk factors.

We have published on a number of traditional vascular risk factors with a focus on differences by race and ethnic- ity. In the United States, Hispanics are one of the most rapidly growing ethnic groups. When NOMAS started there were only a few studies addressing the stroke and brain health risks for this ethnic group. We have addressed traditional risk factors, behavioral risk factors, and published twice on the protective effects of drinking alcohol in moderation that has been corroborated in other studies [17-22]. Physical activity, obesity, and more recently, sleep and migraines have been addressed [2326]. Although dietary factors was never really funded by the original study, we decided to collect the Block dietary food frequency questionnaires and published on a variety of dietary factors including the protective effects of the Mediterranean diet and the deleterious effect of diet soda [27-29]. Social factors, metabolic factors, novel cardiac factors and inflammation and infection have also been studied [30].

Besides individual risk factors, risk profiles that evaluate multiple factors can have a predictive value. The Framingham risk profile is one of the most widely used risk schemes that dates back to the mid-1970s and included serum cholesterol, blood pressure, a smoking history, electrocardiogram findings and glucose intolerance. Kannel stated that this profile was 'effective in identifying persons at risk for each of the specific diseases, coronary heart disease, atherothrombotic brain infarction, hypertensive heart disease and intermittent claudication, even though the variables used have a different impact on each particular disease' [31]. The individual quantitative effects may differ, but all of these risk factors either togeth- 
er or individually increase the risk of vascular disease. The important concept of a risk profile has continued to this day as we seek to refine this original construct.

In NOMAS we set out to create our own global vascular risk score (GVRS) to predict stroke, MI and vascular death among a multi-ethnic cohort and started with the Framingham factors [32]. One of the important differences in the NOMAS GVRS compared to the original Framingham Score is the use of continuous measures. If you think about blood pressure, weight, waist circumference, body mass index, and other risk factors, many of these are continuous variables instead of categorical measures. As clinicians, we often find it easier to create these categories for convenience. If somebody has a blood pressure of 140/90, they are classified as definitely hypertensive and if they are 139/89 they are not. Some of these conventions are done to help us as clinicians make easy decisions on the course of treatment to be followed and are frequently easier for the public to understand. Most of these measures, however, are continuous. If you examine the epidemiological data, it is very clear that there is usually an incrementally increasing risk with increasing levels of these factors. Therefore, in building our NOMAS GVRS, for example, we used systolic and diastolic blood pressure and fasting blood sugar as continuous measurements to provide the full precision of these measures across the whole spectrum. The Framingham profile did not include any behavioral factors. In our NOMAS GVRS, we included waist circumference, physical activity, and moderate alcohol consumption as important modifiable behavioral factors.

Other multi-factorial risk models have been used to predict stroke and cardiovascular risk. In 2010 the American Heart Association launched a campaign to define ideal cardiovascular health as Life's Simple 7 [33]. The presence of these 7 factors would define ideal cardiovascular health: (1) never smoked or quit $>1$ year ago; (2) body mass index $<25 \mathrm{~kg} / \mathrm{m}^{2}$; (3) physical activity of at least $150 \mathrm{~min}$ (moderate intensity) or $75 \mathrm{~min}$ (vigorous intensity) each week; (4) 4-5 key components of a healthy diet consistent with current AHA guidelines; (5) total cholesterol of $<200 \mathrm{mg} / \mathrm{dl}$; (6) blood pressure below $120 / 80 \mathrm{~mm} \mathrm{Hg}$; and (7) fasting blood glucose $<100 \mathrm{mg} /$ $\mathrm{dl}$. The key components for diet were: (1) fruits and vegetables: $\geq 4.5$ cups per day; (2) fish (preferably oily): $\geq 2$ (3.5-oz servings) per week; (3) fiber-rich whole grains (1.1 $\mathrm{g}$ fiber per $10 \mathrm{~g}$ carbohydrate): $\geq 3$ (1-oz-equivalent servings) per day; (4) sodium: $<1,500 \mathrm{mg}$ per day; and (5) sugar sweetened beverages: $\leq 450 \mathrm{kcal}(36-\mathrm{oz})$ per week. Currently, $<0.5 \%$ of the US population meets all 7 metrics for ideal cardiovascular health. The AHA's aggressive goal is to shift the US population by $20 \%$ by 2020 to ideal cardiovascular health.

When we looked at the prevalence of ideal cardiovascular health in NOMAS, nobody had all 7 ideal health factors, and only $0.5 \%$ had 6 factors [34]. When using 4 or more ideal factors as a category, we noted some sex disparities with only $15.3 \%$ of women and $25 \%$ of men meeting this threshold. Ideal cardiovascular health is inadequate throughout the United States as well as many other countries. As many lower to middle income countries develop, we may see even less ideal health in the future with increasing BP, diabetes, obesity, smoking, and less physical activity.

In NOMAS, we evaluated the relationship between baseline ideal cardiovascular health and the incidence of MI, stroke, and vascular death in our prospective cohort over 10 years of follow-up. Subjects with the greatest number of ideal factors had the least incidence of combined outcomes, while those with the least number of ideal factors had the greatest incidence of stroke, MI or vascular death. The trend was clear across the separate outcomes of MI, stroke and vascular death. Therefore, multiple lines of evidence have shown us that more ideal cardiovascular health is associated with decreasing risk of vascular disease [35-38]. What is also apparent when you look at ideal health is not just the effects of control of blood pressure, cholesterol, and glucose that are often treated with medications, but also the impact of increasing number of ideal behavioral factors. For any increase in the number of ideal health behaviors, we saw a reduction in the risk of stroke, MI and vascular death even among those with three of the ideal health factors of blood pressure, cholesterol and blood sugar (fig. 2). Health behaviors, such as physical activity, smoking, BMI and diet, are often not emphasized enough in our patient encounters. Diet is one of the most important reasons why the US population is so far off the ideal health spectrum.

Besides predicting lower risks of stroke, MI and vascular death, it is reasonable to presume that ideal cardiovascular health is a determinant of brain health. We have new unpublished data from NOMAS on the relationship of neuropsychological assessments of language, executive function, memory and processing speed and how they relate to ideal cardiovascular health. Using the baseline cognitive assessment, processing speed significantly varied with the number of ideal factors. The more ideal health, the better the subject scored for processing speed. Among those with good baseline cognitive function, cognitive declines for executive function, episodic memory, 
Fig. 2. Numbers of ideal health factors and behaviors and incidence of MI, stroke or vascular death in the NOMAS (adapted from Circulation 2012;125:2975-2984).

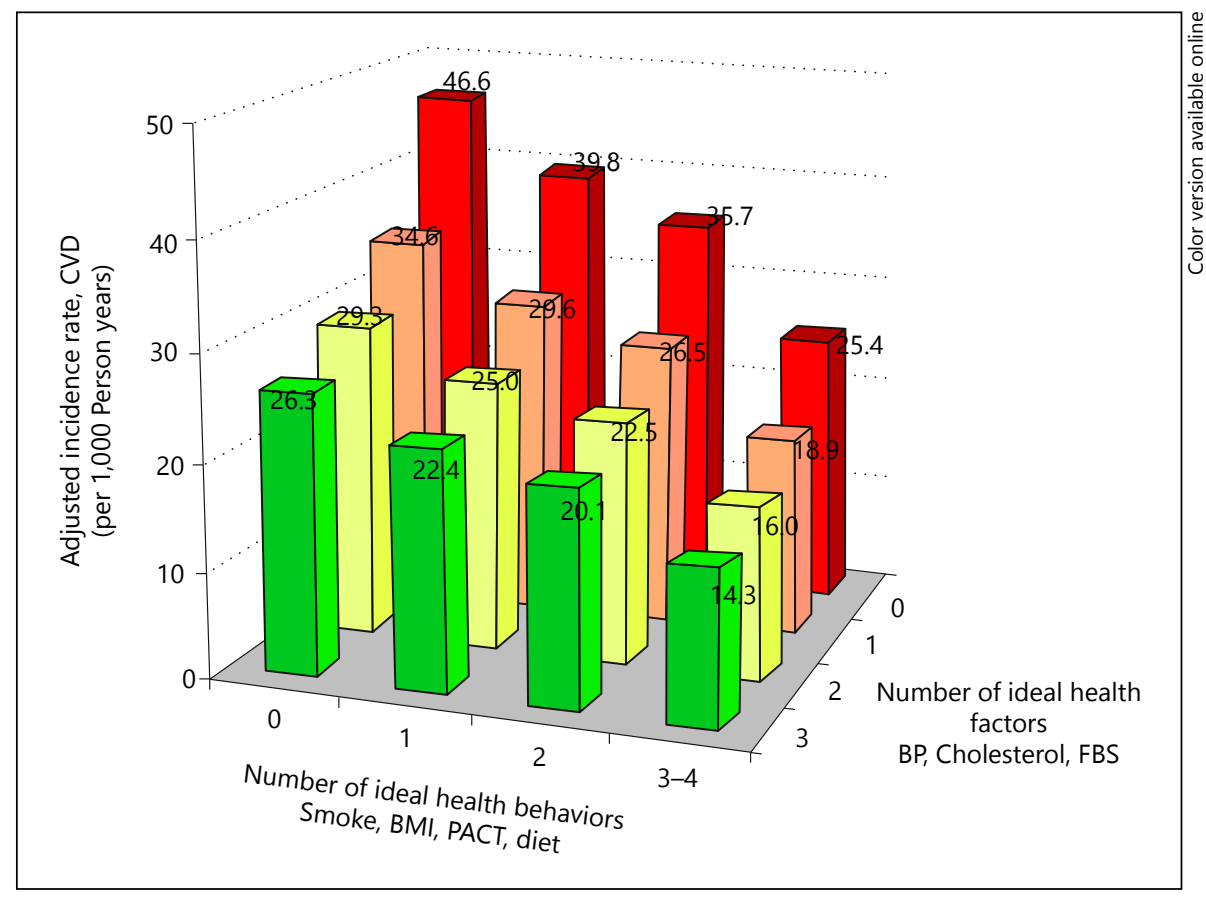

and processing speed were found among those with the least numbers of ideal factors. Therefore, ideal cardiovascular health is a predictor of stroke, MI, and vascular death, as well as measures of cognition and cognitive decline. This is not just indicative of vascular cognitive impairment; rather this is cognition measured on neuropsychological testing in a community sample.

Recently, we also demonstrated a relationship between functional decline and ideal cardiovascular health [39, 40]. We classified this decrement in the Barthel Activities of Daily Living score with decreasing number of ideal factors as 'vascular functional impairment'. The subjects with greater number of ideal factors had less functional decline. Even if you accounted for any vascular events, there were still functional decrements in those with less ideal health. This adds functional impairment to our broader concept of brain health beyond stroke.

Besides multiple risk factor scores and ideal cardiovascular health, the construct of the metabolic syndrome is another example of a multiple risk factor determined condition that is designed to classify someone much earlier than they are diagnosed with diabetes. To be classified as having metabolic syndrome, one has to have 3 or more of these conditions: (1) borderline low HDL-C $(\mathrm{M}<40$ $\mathrm{mg} / \mathrm{dl}, \mathrm{F}<50 \mathrm{mg} / \mathrm{dl}$ ); (2) triglycerides that are borderline elevated (triglyceride $>150 \mathrm{mg} / \mathrm{dl}$ ); (3) a blood pressure that is borderline elevated (BP $>130 / 85$ or HTN history);
(4) a mildly elevated fasting blood glucose (blood sugar $>110 \mathrm{mg} / \mathrm{dl}$ ); and (5) a borderline elevated waist circumference (waist $M>108 \mathrm{~cm}, \mathrm{~F}>88 \mathrm{~cm}$ ). In NOMAS we have been able to show that the presence of metabolic syndrome increased the risk of stroke with a hazards ratio of 1.5 and had an etiologic fraction of $42 \%$, which is the portion of strokes in our population that may be attributed to the metabolic syndrome [41]. Each of the individual components is also important, so you can break things down by individual risk factors or you can evaluate the combined risk associated with a constellation of risk factors. If you consider the combined approach, which is probably more typical in our clinics, we actually have multiple factors working in concert. Metabolic syndrome, comparable to the multiple risk factor models, is another example of the importance of the concept of vascular risk clusters as predictors of stroke.

Just as with ideal cardiovascular health in NOMAS, we have been able to model associations between metabolic syndrome, the individual components, overall cognition and specific cognitive domains [42, 43]. Metabolic risk measured by metabolic syndrome loads on to our overall cognitive function score with a very negative coefficient. We also evaluated the individual components of metabolic syndrome and observed that the obesity component was associated with psychomotor function, lipids affected language, fasting glucose affected psychomotor function, 
and blood pressure had associations with language, executive function, and psychomotor speed. This data suggest that metabolic syndrome and the components have an impact on, not only stroke, but also cognitive function, and adds to the brain health construct.

Evaluating measures of sub-clinical disease provides another opportunity for earlier detection and initiation of treatments and prevention measures. The concept can also be illustrated by the iceberg analogy. Above the surface, we are getting involved when the individual already has clinical symptoms such as a stroke. Beneath the surface, sub-clinical measurements will hopefully help us detect people earlier and treat them and intervene before they have their event.

In NOMAS, we have evaluated a number of these subclinical measurements and conditions. For carotid disease, it is not just carotid stenosis, but carotid plaque and IMT that are very important in detecting risks. Atrial fibrillation (AF), we know is an undeniable risk factor for stroke, but what about sub-clinical AF, left atrial size, and p-wave terminal velocity? We know about heart failure as a stroke risk factor, especially when it becomes clinically symptomatic, but left ventricular ejection fractions (EFs) that are mild or global longitudinal strain (GLS) may also be risk factors. Among our cerebrovascular measures, white matter disease, silent brain infarcts (SBI), small perivascular spaces (SPVS), and dolichoectasia may be risk determinants. The earlier we measure and detect these conditions, the more opportunities we may have to alter that eventual progression to stroke and vascular cognitive impairment.

Dr. Tatjana Rundek has helped tremendously direct many of our carotid studies in NOMAS regarding stenosis, IMT and plaque. She was able to demonstrate that a small amount of carotid plaque that would not get our interventionalists or surgeons too excited, was predictive of vascular events. In the NOMAS population, a plaque thickness of $1.8 \mathrm{~mm}$ was the 75 th percentile; consequently, $25 \%$ of the cohort had more than $1.8 \mathrm{~mm}$ of plaque [6]. This amount of carotid plaque was found to be a very important, independent determinant of stroke and vascular death even after fully adjusting for all the other vascular risk factors. Having a very small amount of plaque in the carotid that can be detected by ultrasound is a risk determinant of stroke and cardiovascular death and provides an opportunity for earlier detection.

Having worked with cardiology colleagues in NOMAS, we have evaluated and published information on many other cardiac abnormalities as predictors of stroke including patent foramen ovale, atrial septal defect, aortic arch atheroma, LV EF, and have studied multiple subclinical measures such as atrial volumes by cardiac echo, GLS on echo, $p$-wave terminal velocity in V1 by EKG, and subclinical AF. These subclinical cardiac measurements, similar to the carotid, could allow early detection and identification of risk.

One innovative subclinical cardiac measure that we have recently evaluated is GLS that is calculated from echocardiographic measurements of the shortening of the myocardial fibers. The goal of this type of measurement is to more finely classify individuals who would usually be considered normal by traditional EF classifications. We can categorize subjects into 3 groups: (1) left ventricular systolic dysfunction for those with LV EF $<50 \%$; (2) left ventricular systolic dysfunction by abnormal GLS with LV EF $>50 \%$; and (3) normal - normal GLS and LV EF $>50 \%$. Dr. Russo has been able to show that despite an LV EF $>50 \%$, this GLS-defined intermediate category has an elevated risk of stroke, MI and vascular death (HR 2.15, 1.09-4.23) [44]. In the NOMAS sample, only $4 \%$ had an $\mathrm{EF}<50 \%$, while the prevalence of systolic dysfunction increased to almost $15 \%$ if you use GLS categorizations. Besides an increased risk of stroke, MI, and vascular death, we have also found correlations between the SBI and GLS subgroups [45]. Those with LV SD by GLS had a greater prevalence of SBI, as well as a greater white matter hyper-intensity volume. This is yet another example of quantitative subclinical measurements defining new subgroups of increased risk of stroke, as well as a brain health determinant.

Atrial fibrillation is a well-recognized stroke risk factor, but is likely to be heralded by some precursor conditions. In preliminary studies, we have found the LV SD by GLS may be a predictor of the incidence of atrial fibrillation. There may be other abnormalities, including abnormalities in the left atrium that can increase the risk of stroke without atrial fibrillation, which has been categorized as an 'atrial cardiopathy' by Kamel et al. [46]. Using stored EKGs in NOMAS, we have been able to measure what is called p-wave terminal force in $\mathrm{V} 1$ - duration $\mathrm{X}$ amplitude (depth) of the negative part of the p-wave in V1. This measurement has been found to be associated with the risk of AF [47]. Moreover, we have recently demonstrated that this may be an independent ischemic stroke risk factor even after adjusting for AF. The risk of cryptogenic and cardioembolic stroke was increased among those with an abnormal p-wave terminal force in V1, more so than a non-cardioembolic stroke. This describes yet another example of some subclinical measurement that may be a novel risk factor for stroke. 
Fig. 3. Relationship between NOMAS GVRS and subclinical brain measures (adjusted beta coefficients as percentage of TCV adjusted for socioeconomic status and disease history by GVRS quartiles with 1 st quartile as reference group).

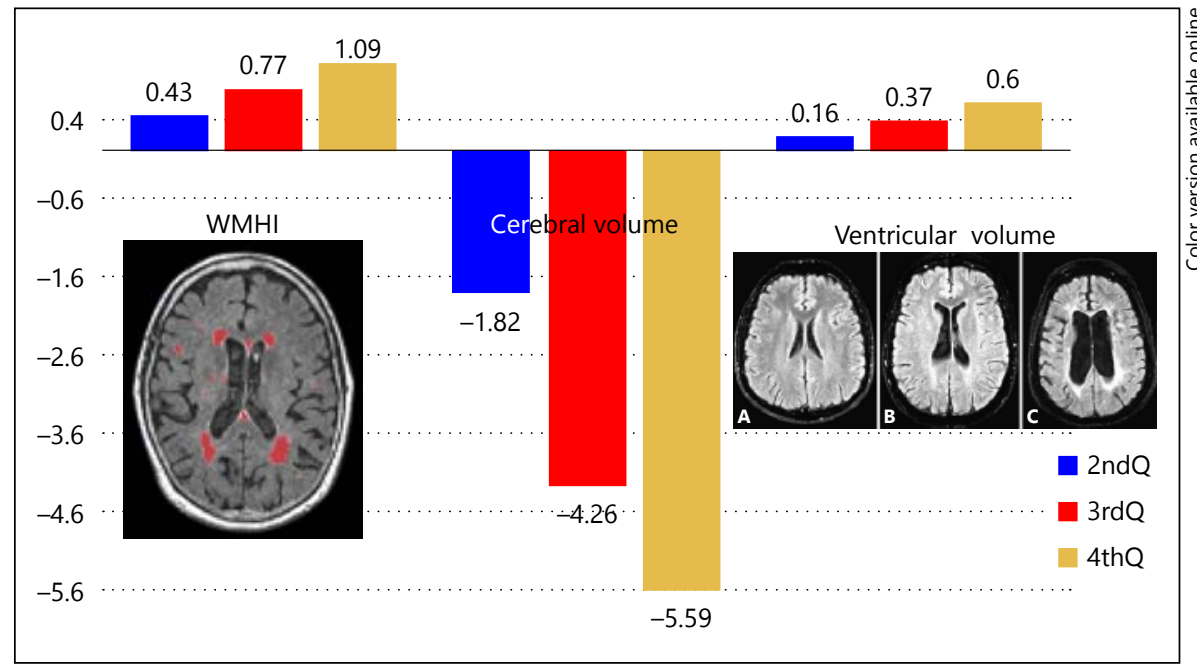

Brain MRI has also allowed us to characterize sub-clinical vascular brain injuries such as WMHI and SBI and evaluate them as stroke risk factors and brain health determinants. They are frequently found on MRIs especially in older individuals. Dr. Clinton Wright has led our efforts to measure these among 1,300 NOMAS subjects [48-50]. Our own data and that of others have demonstrated that SBI and WMHI are stroke risk factors. We have quantitated the volume of WMHI and treated it as a continuous variable rather than a categorical variable. The NOMAS GVRS was significantly related to the volume of WMHI, as well as total cranial volume and ventricular volume suggesting that cerebal atrophy is also related to the burden of vascular risk. Those subjects with a worse GVRS had more cortical atrophy, greater ventricular volume, and an increased volume of WMHI (fig. 3). All of these brain MRI measures may be subclinical correlates of vascular disease and these subclinical measures can be readily identified, categorized and quantitated.

$\mathrm{WMHI}$ is associated with vascular risk factors and has been correlated with cognitive impairment and decline. Those subjects with the worst white matter scores have the greatest likelihood of worse cognitive function and cognitive decline [51]. Using our annual telephone interview for cognitive state (TICS) data, we have demonstrated that declines in TICS are greater among those subjects with increased WMHI.

SBI have been identified as a risk factor for stroke in a number of cohorts [52]. We recently showed NOMAS data at the American Academy of Neurology that demonstrates that the presence of an SBI independently increased the risk of a subsequent clinical infarct even after adjusting for other vascular risk factors. Subclinical brain measurements are another example of the evolution from stroke risk factors to brain health determinants that can be used to quantitate brain health including stroke and cognitive aging.

Some other brain MRI measures that Jose Gutierrez has been evaluating include dolichoectesia (DE) and SPVS [53]. He has been able to show that DE measured quantitatively in the NOMAS population has important vascular determinants. SPVS that are measured on MRI have been labeled as incidental findings. In NOMAS, SPVS were significantly increased among those who had more vascular risk factors [54]. The next questions are whether DE and SPVS also increase stroke risk, as well as cognitive decline.

In NOMAS, we have also addressed other novel determinants of stroke risk and brain health. Mitch Elkind has lead our efforts regarding chronic infection and inflammation. Originally he and others questioned whether there could be a stroke bug explaining some atherosclerotic strokes [55]. It is more likely that the impact of multiple chronic infections could be related to increased inflammatory burden and interact with alterations in host immune networks to lead to a greater likelihood of stroke. He has developed the concept of 'infectious burden' and created an infectious burden index (IBI) consisting of a multiplicity of chronic infection exposures including CMV, Chlamydia pneumoniae, $H$. pylori, HSV and other common infectious agents [56]. The IBI was created in our NOMAS cohort and then related to subsequent vascular disease and cognitive outcomes [57]. We have shown that those who have a greater IBI have a significantly elevated relative risk 


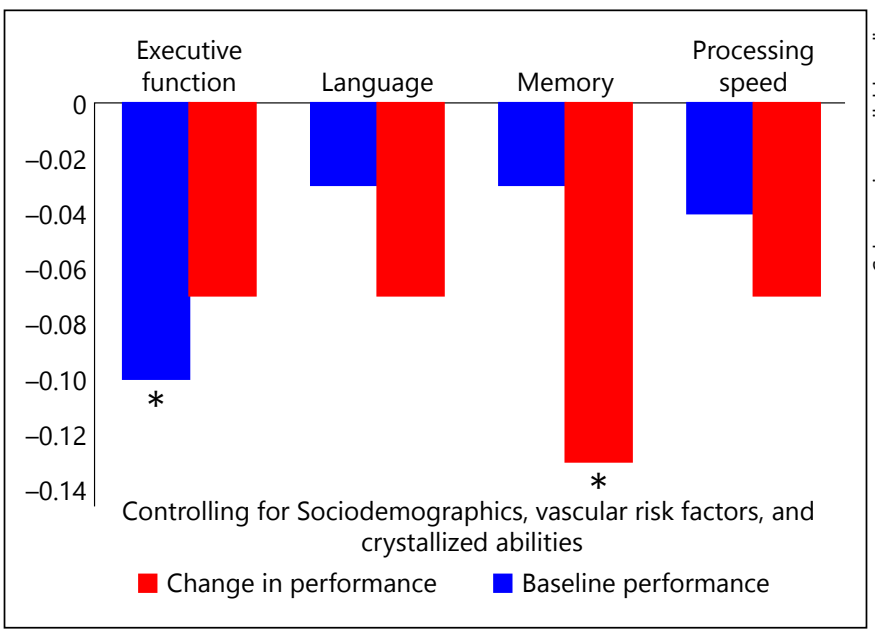

Fig. 4. Relationship between the IBI and baseline cognitive status and cognitive declines across selected domains in the NOMAS.

of stroke, as well as MI and vascular death. Moreover, we have been able to show that the IBI also has a significant relationship with cognitive status measured by the MiniMental State Exam and the TICS [58]. Just as our global vascular risk model and number of ideal cardiovascular health metrics are correlated with cognition, so is the IBI. Using our serial neuropsychological assessments, we have also shown that IBI is related to individual subscores of executive function, language, memory, and processing speed, and that IBI is related to cognitive decline across memory and executive function cognitive domains (fig. 4).

What about the future? Our future plans in NOMAS are to expand beyond infectious burden and address inflammatory burden. We are planning to look at a variety of other inflammatory markers and use network analyses to evaluate networks of inflammatory and immune markers working within a constellation of host factors together to influence stroke risk, vascular disease, as well as brain health.

The broader concept of brain health provides an expanded opportunity to address modifiable factors to improve outcomes for our patients beyond stroke. I look forward to attending future European Brain Health Conferences where the research aspects related to determinants of stroke, cognition, and functional status can be discussed. GVRSs, ideal cardiovascular health, and subclinical vascular measures of the carotid and cardiac function of the left ventricle and atrium are all related to various brain health outcomes. Subclinical brain measures such as WMHI and silent infarcts, and even SPVS may be important determinants of brain health. Novel indices of

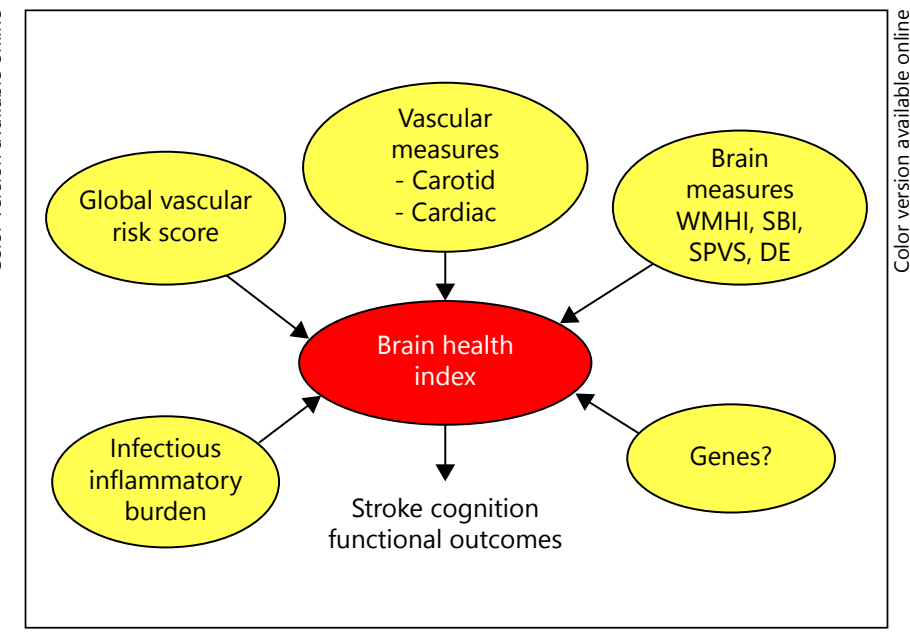

Fig. 5. Brain health determinants.

infectious burden also show associations with brain health that we are still trying to tease apart. How these relationships unfold within the background of a genetic framework are still unanswered questions. Our genetic architecture likely has some role in susceptibility and interacts with many of these environmental determinants to alter our individual risk of stroke and other brain health outcomes. Perhaps instead of stroke risk scores or GVRSs, we will be creating a future brain health index (fig. 5). I think this provides us with an opportunity to think more broadly about prevention.

Tackling the growing burden of non-communicable diseases is a new global goal. The UN and WHO have made a political proclamation of aiming for a $25 \%$ reduction in premature mortality from non-communicable disease, including cardiovascular diseases, stroke, cancer, diabetes, and chronic lung diseases, by 2025. Most of the international targets for 2025 are still on the traditional health factors - many factors that have been defined by ideal cardiovascular health, including smoking, physical activity, alcohol, sodium, blood pressure and diabetes. We still have great challenges in effectively modifying behaviors and controlling these health factors, let alone tackling any of the novel risk factors that we are still trying to define in Northern Manhattan. The future is going to mean looking further beyond stroke and mortality, and require thinking more broadly about brain health, cognition and functional decline.

In closing, the future burden of stroke and impaired brain health is grave and is likely to increase when you think about the aging trends of our populations across 
every nation. Improving ideal cardiovascular health can reduce stroke, MI and vascular death, but also improve cognition. Risk factors, continuous markers, and subclinical determinants refine risk prediction and encourage earlier prevention. Novel risk factors and determinants can elucidate innovative future approaches to improve brain health. Prevention requires detecting and treating determinants of risk as early as possible, long before any clinical symptoms manifest. We are hoping to expand the scope of neurologists to become vascular interventionalists, as well as preventative vascular neurologists. The bottom line is that we need to collaborate as teams within our individual communities, across countries, and across regions, to accomplish these health targets and improve population health if we are ever going to achieve the 2025 global goals for health.
I am thankful to the NINDS for the research support I have had over the years. I am grateful to all the colleagues and teams I have worked with at Columbia and at the University of Miami. I am thankful for my partner and my family for supporting me. I would not be here today delivering this Wepfer lecture without all their support.

\section{Acknowledgements}

Dr. Sacco is supported by grants from NIH (R37 NS 29993, U54 NS 081763, R01 NS 240807, R01 42912, 047655, DE 13094), the American Heart Association/American Stroke Association Bugher Center of Excellence, and the Evelyn McKnight Brain Institute. Dr. Sacco has served as a consultant for Boehringer Ingelheim for the RE-SPECT ESUS Trial.
A Summary points

(1) Traditional vascular risk factors are determinants of stroke, but also brain health, and this will become increasingly important as our populations age.

(2) Risk factor combinations, as opposed to individual risk factors, are useful to help identify individuals who are at risk for threats to their brain health.

(3) Risk is usually continuous and cumulative and there are important precursor behavioral or lifestyle conditions that precede the actual risk factor.

(4) Sub-clinical vascular and brain measures are determinants of brain health, and will enhance opportunities for us to detect and initiate treatments and prevention before one has a stroke or before one has a decrement in brain health.

(5) Novel factors such as infectious burden and inflammatory markers are determinants of not only stroke, but also brain health.

\section{$B$ Brain health determinants}

Traditional factors

(1) Lifestyle factors

- Smoking, physical activity, excess alcohol use, obesity, and diet

(2) Conditions

- Hypertension, diabetes, hypercholesterolemia

- Cardiac disease, atrial fibrillation

Subclinical measurements

(1) Carotid

- Carotid plaque, intima-media thickness

(2) Cardiac

- Subclinical AF, left atrial size, p-wave terminal velocity $\mathrm{EF}, \mathrm{GLS}$, left ventricular mass

(3) Brain

- White matter hyperintensities

- SBI

- SPVS

- Dolichoectasia

\section{References}

1 Sacco RL, Wolf PA, Kannel WB, McNamara PM: Survival and recurrence following stroke. The Framingham Study. Stroke 1982;13:290295.

2 Feigin VL, Forouzanfar MH, Krishnamurthi R, Mensah GA, Connor M, Bennett DA, Moran AE, Sacco RL, Anderson L, Truelsen T, O'Donnell M, Venketasubramanian N, Barker-Collo S, Lawes CM, Wang W, Shinohara Y, Witt E, Ezzati M, Naghavi M, Murray C; Global Burden of Diseases, Injuries, and Risk Factors Study 2010 (GBD 2010) and the GBD Stroke Experts Group: Global and regional burden of stroke during 1990-2010: findings from the Global Burden of Disease Study 2010. Lancet 2014;383:245-254.

3 Blazer DG, Yaffe K, Liverman CT (eds): Cognitive Aging: Progress in Understanding and Opportunities for Action. Washington, National Academies Press, 2015. http://www.iom. edu/cognitiveaging (accessed April 14, 2015).

4 Kannel WB, Dawber TR, Kagan A, Revotskie $\mathrm{N}$, Stokes J 3rd: Factors of risk in the development of coronary heart disease - six year follow-up experience. The Framingham Study. Ann Intern Med 1961;55:33-50.

5 Sacco RL, Boden-Albala B, Gan R, Kargman DE, Paik M, Shea S, Hauser WA: Stroke inci- dence among white, black, and Hispanic residents of an urban community: the Northern Manhattan Stroke Study. Am J Epidemiol 1998;147:259-268.

6 Gardener H, Sjoberg C, Crisby M, Goldberg R, Mendez A, Wright CB, Elkind MS, Sacco $\mathrm{RL}$, Rundek T: Adiponectin and carotid intima-media thickness in the Northern Manhattan Study. Stroke 2011;43:1123-1125.

7 Rundek T, Arif H, Boden-Albala B, Elkind MS, Paik MC, Sacco RL: Carotid plaque, a subclinical precursor of vascular events: the Northern Manhattan Study. Neurology 2008; 70:1200-1207. 
8 Kuo F, Gardener H, Dong C, Cabral D, DellaMorte D, Blanton SH, Elkind MS, Sacco RL, Rundek T: Traditional cardiovascular risk factors explain the minority of the variability in carotid plaque. Stroke 2012;43:1755-1760.

9 Alsulaimani S, Gardener H, Elkind MS, Cheung K, Sacco RL, Rundek T: Elevated homocysteine and carotid plaque area and densitometry in the Northern Manhattan Study. Stroke 2013;44:457-461.

10 Rundek T, Blanton SH, Bartels S, Dong C, Raval A, Demmer RT, Cabral D, Elkind MS, Sacco RL, Desvarieux M: Traditional risk factors are not major contributors to the variance in carotid intima-media thickness. Stroke 2013; 44:2101-2108.

11 Di Tullio MR, Sacco RL, Sciacca RR, Homma S: Left atrial size and the risk of ischemic stroke in an ethnically mixed population. Stroke 1999;30:2019-2024.

12 Kohsaka S, Sciacca RR, Sugioka K, Sacco RL, Homma S, Di Tullio MR: Electrocardiographic left atrial abnormalities and risk of ischemic stroke. Stroke 2005;36:2481-2483.

13 Di Tullio MR, Zwas DR, Sacco RL, Sciacca RR, Homma S: Left ventricular mass and geometry and the risk of ischemic stroke. Stroke 2003;34:2380-2384.

14 Di Tullio MR, Sacco RL, Sciacca RR, Jin Z, Homma S: Patent foramen ovale and the risk of ischemic stroke in a multiethnic population. J Am Coll Cardiol 2007;49:797-802.

15 Di Tullio MR, Jin Z, Russo C, Elkind MS, Rundek T, Yoshita M, Decarli C, Wright CB, Homma S, Sacco RL: Patent foramen ovale, subclinical cerebrovascular disease, and ischemic stroke in a population-based cohort. J Am Coll Cardiol 2013;62:35-41.

16 Russo C, Jin Z, Liu R, Homma S, Elkind MS, Rundek T, DeCarli C, Wright CB, Sacco RL, Di Tullio MR: LA volumes and reservoir function are associated with subclinical cerebrovascular disease: the cardiac abnormalities and brain lesions (CABL) study. JACC Cardiovasc Imaging 2013;6:313-323.

17 Sacco RL, Elkind M, Boden-Albala B, Lin IF, Kargman DE, Hauser WA, Shea S, Paik MC: The protective effect of moderate alcohol consumption on ischemic stroke. JAMA 1999; 281:53-60.

18 Elkind MS, Sciacca R, Boden-Albala B, Rundek T, Paik MC, Sacco RL: Moderate alcohol consumption reduces risk of ischemic stroke: the Northern Manhattan Study. Stroke 2006;37:13-19.

19 Boden-Albala B, Cammack S, Chong J, Wang C, Wright C, Rundek T, Elkind MS, Paik MC, Sacco RL: Diabetes, fasting glucose levels, and risk of ischemic stroke and vascular events: findings from the Northern Manhattan Study (NOMAS). Diabetes Care 2008;31:11321137.

20 Boden-Albala B, Kargman DE, Lin IF, Paik MC, Sacco RL, Berglund L: Increased stroke risk and lipoprotein(a) in a multiethnic community: the Northern Manhattan Stroke Study. Cerebrovasc Dis 2010;30:237-243.
21 Banerjee C, Moon YP, Paik MC, Rundek T, Mora-McLaughlin C, Vieira JR, Sacco RL, Elkind MS: Duration of diabetes and risk of ischemic stroke: the Northern Manhattan Study. Stroke 2012;43:1212-1217.

22 Willey JZ, Moon YP, Kahn E, Rodriguez CJ, Rundek T, Cheung K, Sacco RL, Elkind MS: Population attributable risks of hypertension and diabetes for cardiovascular disease and stroke in the Northern Manhattan Study. J Am Heart Assoc 2014;3:e01106.

23 Sacco RL, Gan R, Boden-Albala B, Lin IF, Kargman DE, Hauser WA, Shea S, Paik MC: Leisure-time physical activity and ischemic stroke risk: the Northern Manhattan Stroke Study. Stroke 1998;29:380-387.

24 Willey JZ, Moon YP, Paik MC, Boden-Albala B, Sacco RL, Elkind MS: Physical activity and risk of ischemic stroke in the Northern Manhattan Study (NOMAS). Neurology 2009;73: 1774-1779.

25 Boden-Albala B, Roberts ET, Bazil C, Moon Y, Elkind MS, Rundek T, Paik MC, Sacco RL: Daytime sleepiness and risk of stroke and vascular disease: findings from the Northern Manhattan Study (NOMAS). Circ Cardiovasc Qual Outcomes 2012;5:500-507.

26 Monteith T, Gardener H, Rundek T, Dong C, Yoshita M, Elkind MS, DeCarli C, Sacco RL, Wright C: Migraine, white matter hyperintensities, and subclinical brain infarction in a diverse community: the Northern Manhattan Study. Stroke 2014;45:1830-1832.

27 Gardener H, Wright CB, Gu Y, Demmer RT, Boden-Albala B, Elkind MS, Sacco RL, Scarmeas N: Mediterranean-style diet and risk of ischemic stroke, myocardial infarction, and vascular death: the Northern Manhattan Study. Am J Clin Nutr 2011;94:1458-1464.

28 Gardener H, Rundek T, Markert M, Wright CB, Elkind MS, Sacco RL: Diet soft drink consumption is associated with an increased risk of vascular events in the Northern Manhattan Study. J Gen Intern Med 2012;27:1120-1126.

29 Gardener H, Rundek T, Wright CB, Elkind MS, Sacco RL: Dietary sodium and risk of stroke in the Northern Manhattan Study. Stroke 2012;43:1200-1205.

30 Rundek T, Gardener H, Xu Q, Goldberg RB, Wright CB, Boden-Albala B, Disla N, Paik MC, Elkind MS, Sacco RL: Insulin resistance and risk of ischemic stroke among nondiabetic individuals from the Northern Manhattan Study. Arch Neurol 2010;67:1195-1200.

31 Kannel WB, McGee D, Gordon T: A general cardiovascular risk profile: the Framingham Study. Am J Cardiol 1976;38:46-51.

32 Sacco RL, Khatri M, Rundek T, Xu Q, Gardener $\mathrm{H}$, Boden-Albala B, Di Tullio MR, Homma S, Elkind MS, Paik MC: Improving global vascular risk prediction with behavioral and anthropometric factors. The multiethnic NOMAS (Northern Manhattan Cohort Study). J Am Coll Cardiol 2009;54:2303-2311.

33 Lloyd-Jones DM, Hong Y, Labarthe D, Mozaffarian D, Appel LJ, Van Horn L, Greenlund K, Daniels S, Nichol G, Tomaselli GF, Arnett
DK, Fonarow GC, Ho PM, Lauer MS, Masoudi FA, Robertson RM, Roger V, Schwamm LH, Sorlie P, Yancy CW, Rosamond WD; American Heart Association Strategic Planning Task Force and Statistics Committee: Defining and setting national goals for cardiovascular health promotion and disease reduction: the American Heart Association's strategic impact goal through 2020 and beyond. Circulation 2010;121:586-613.

34 Dong C, Rundek T, Wright CB, Anwar Z, Elkind MS, Sacco RL: Ideal cardiovascular health predicts lower risks of myocardial infarction, stroke, and vascular death across Whites, Black, and Hispanics: the Northern Manhattan Study. Circulation 2012;125:2975-2984.

35 Folsom AR, Yatsuya H, Nettleton JA, Lutsey PL, Cushman M, Rosamond WD; ARIC Study Investigators: Community prevalence of ideal cardiovascular health, by the American Heart Association definition, and relationship with cardiovascular disease incidence. J Am Coll Cardiol 2011;57:1690-1696.

36 Xanthakis V, Enserro DM, Murabito JM, Polak JF, Wollert KC, Januzzi JL, Wang TJ, Tofler G, Vasan RS: Ideal cardiovascular health: associations with biomarkers and subclinical disease and impact on incidence of cardiovascular disease in the Framingham Offspring Study. Circulation 2014;130:1676-1683.

37 Zhang Q, Zhou Y, Gao X, Wang C, Zhang S, Wang A, Li N, Bian L, Wu J, Jia Q, Wu S, Zhao $\mathrm{X}$ : Ideal cardiovascular health metrics and the risks of ischemic and intracerebral hemorrhagic stroke. Stroke 2013;44:2451-2456.

38 Ford ES, Greenlund KJ, Hong Y: Ideal cardiovascular health and mortality from all causes and diseases of the circulatory system among adults in the United States. Circulation 2012; 125:987-995.

39 Dhamoon MS, Moon YP, Paik MC, Sacco RL, Elkind MS: Diabetes predicts long-term disability in an elderly urban cohort: the Northern Manhattan Study. Ann Epidemiol 2014;24:362-368.

40 Dhamoon MS, Dong C, Elkind MS, Sacco RL: Ideal cardiovascular health predicts functional status independently of vascular events: the Northern Manhattan Study. J Am Heart Assoc 2015;4:e001322.

41 Boden-Albala B, Sacco RL, Lee HS, GrahameClarke C, Rundek T, Elkind MV, Wright C, Giardina EG, DiTullio MR, Homma S, Paik MC: Metabolic syndrome and ischemic stroke risk: the Northern Manhattan Study. Stroke 2008;39:30-35.

42 Vieira JR, Elkind MS, Moon YP, Rundek T, Boden-Albala B, Paik MC, Sacco RL, Wright CB: The metabolic syndrome and cognitive performance: the Northern Manhattan Study. Neuroepidemiology 2011;37:153-159.

43 Levin BE, Llabre MM, Dong C, Elkind MS, Stern Y, Rundek T, Sacco RL, Wright CB: Modeling metabolic syndrome and its association with cognition: the Northern Manhattan Study. J Int Neuropsychol Soc 2014;20: 951-960. 
44 Russo C, Jin Z, Elkind MS, Rundek T, Homma S, Sacco RL, Di Tullio MR: Prevalence and prognostic value of subclinical left ventricular systolic dysfunction by global longitudinal strain in a community-based cohort. Eur J Heart Fail 2014;16:1301-1309.

45 Russo C, Jin Z, Homma S, Elkind MS, Rundek T, Yoshita M, DeCarli C, Wright CB, Sacco RL, Di Tullio MR: Subclinical left ventricular dysfunction and silent cerebrovascular disease: the cardiovascular abnormalities and brain lesions (CABL) study. Circulation 2013; 128:1105-1111.

46 Kamel H, Okin PM, Longstreth WT Jr, Elkind MS, Soliman EZ: Atrial cardiopathy: a broadened concept of left atrial thromboembolism beyond atrial fibrillation. Future Cardiol 2015;11:323-331.

47 Magnani JW, Zhu L, Lopez F, Pencina MJ, Agarwal SK, Soliman EZ, Benjamin EJ, Alonso A: P-wave indices and atrial fibrillation: cross-cohort assessments from the Framingham Heart Study (FHS) and atherosclerosis risk in communities (ARIC) study. Am Heart J 2015;169:53-61.e1.

48 Wright CB, Moon Y, Paik MC, Brown TR, Rabbani L, Yoshita M, DeCarli C, Sacco R, El- kind MS: Inflammatory biomarkers of vascular risk as correlates of leukoariosis. Stroke 2009;40:3466-3471.

49 Prabhakaran S, Wright CB, Yoshita M, Delapaz R, Brown T, DeCarli C, Sacco RL: Prevalence and determinants of subclinical brain infarction: the Northern Manhattan Study. Neurology 2008;70:425-430.

50 Marcus J, Gardener H, Rundek T, Elkind MS, Sacco RL, Decarli C, Wright CB: Baseline and longitudinal increases in diastolic blood pressure are associated with greater white matter hyperintensity volume: the Northern Manhattan Study. Stroke 2011;42:2639-2641.

51 Wright CB, Festa JR, Paik MC, Schmiedigen A, Brown TR, Yoshita M, DeCarli C, Sacco R, Stern Y: White matter hyperintensities and subclinical infarction: associations with psychomotor speed and cognitive flexibility. Stroke 2008;39:800-805.

52 Fanning JP, Wong AA, Fraser JF: The epidemiology of silent brain infarction: systematic review of population-based cohorts. BMC Med 2014;12:119.

53 Gutierrez J, Bagci A, Gardener H, Rundek T, Ekind MS, Alperin N, Sacco RL, Wright CB: Dolichoectasia diagnostic methods in a multi- ethnic, stroke-free cohort: results from the Northern Manhattan Study. J Neuroimaging 2014;24:226-231

54 Gutierrez J, Rundek T, Ekind MS, Sacco RL Wright CB: Perivascular spaces are associated with atherosclerosis: an insight from the Northern Manhattan Study. AJNR Am J Neuroradiol 2013;34:1711-1716.

55 Elkind MS: Infectious burden: a new risk factor and treatment target for atherosclerosis. Infect Disord Drug Targets 2010;10:8490.

56 Elkind MS, Ramakrishnan P, Moon YP, Boden-Albala B, Liu KM, Spitalnik SL, Rundek T, Sacco RL, Paik MC: Infectious burden and risk of stroke: the Northern Manhattan Study. Arch Neurol 2010;67:3338.

57 Elkind MS, Luna JM, Moon YP, Boden-Albala B, Liu KM, Spitalnik S, Rundek T, Sacco RL, Paik MC: Infectious burden and carotid plaque thickness: the Northern Manhattan Study. Stroke 2010;41:e117-e122.

58 Katan M, Moon YP, Paik MC, Sacco RL, Wright CB, Elkind MS: Infectious burden and cognitive function: the NOMAS. Neurology 2013;80:1209-1215. 